\title{
Demography and symptom severity of obsessive compulsive disorder in Bangladesh: a cross-sectional observation
}

\author{
Sultana Algin, ${ }^{1}$ Mohammad Waliul Hasnat Sajib, ${ }^{2}$ SM Yasir Arafat ${ }^{3}$ \\ ${ }^{1}$ Associate Professor, Department of Psychiatry, Bangabandhu Sheikh Mujib Medical University (BSMMU), Dhaka, Bangladesh; \\ ${ }^{2}$ Assistant Registrar, Pabna Medical College Hospital, Pabna, Bangladesh; ${ }^{3}$ Resident, Department of Psychiatry, BSMMU, \\ Dhaka, Bangladesh.
}

$\begin{array}{ll}\text { Article info } & \\ \text { Received } & : \text { 06 Apr. } 2018 \\ \text { Accepted } & : \text { 01 Aug. } 2018 \\ \text { Number of tables } & : 03 \\ \text { Number of figures } & : 03 \\ \text { Number of refs } & : 15\end{array}$

Correspondence

Sultana Algin

Mobile: +8801552314981

E-mail: algin28@gmail.com

\begin{abstract}
Summary
Obsessive Compulsive Disorder (OCD) is a common disorder and usually runs a chronic course with waxing and waning course. It leads to pervasive impairments in multiple domains of life. The aim of the study was to assess the demographic characteristics of the OCD patients and symptom severity of this disorder. This was a cross-sectional study done in OCD clinic of outpatient department (OPD) of BSMMU, during the period from May, 2015 to April, 2017. Four hundred patients fulfilling the inclusion and exclusion criteria were selected consecutively. After taking written consent a predetermined questionnaire was filled for each patient through face-to-face interview. Then patients were evaluated covering the following areas: Axis I diagnoses (DSM-IV) and Y-BOCS severity scale. The results showed that, the mean age of the respondents was 26.6 ( $S D \pm 9.9)$ years, ranging from 8 to 63 years. According to Y-BOCS symptoms severity used for adult patients found that majority $(70 \%)$ of the patients had moderate to severe sufferings. Male had co-morbid anxiety disorders (panic disorder, agoraphobia, social phobia) more but female patients were found more depressive disorders. Female had more hypothyroidism, diabetes, skin disorders and hypertension than male. These demographic status, co-morbidity profile and symptoms severity can serve as the baseline data for a country like Bangladesh and further large scale, multi-centered study would better generalize the study results.
\end{abstract}

Bang J Psychiatry 2016;30(2):23-6

\section{Introduction}

Obsessive Compulsive Disorder (OCD) is a common chronic debilitating psychiatric disorder, which affects about $1-3 \%$ of the population world wide. ${ }^{1-4}$ Epidemiological studies conducted in several countries reported current prevalence around $1 \%$ and lifetime prevalence ranging from $2 \%$ to $3 \%$. 5,6 Among adults, men and women are equally likely to be affected, but among adolescent boys are more commonly affected than girls. ${ }^{2,3}$ Studies assessing pediatric samples report male preponderance $(70 \%)$, whereas adult studies report equal gender distribution or a slight female preponderance. ${ }^{7,8}$ Regarding gender, a bimodal distribution of age of onset has been described. The mean age of onset is about 20 years, although men have slightly earlier age of onset (mean about 19 years) than women (mean about 22 years). Overall, the symptoms of about two thirds of affected persons have an onset before the age of 25 years. Male patients usually report early onset of Obsessive-Compulsive Symptoms (OCS) and its association with tic disorders, Attention Deficit Hyperactivity Disorder (ADHD) and anxiety disorders. Two-thirds of the patients with OCD have a major depressive episode during their lifetimes. ${ }^{1}$ Some studies have also reported that women with OCD presented with an abrupt onset of illness having an episodic course with precipitating stressful life events, whereas men generally had an insidious onset with a chronic course and higher symptom severity. A study in Bangladesh found that of the obsession, contamination was the highest followed by doubt, and of the compulsion, washing or cleaning was the highest followed by checking, repeating, and ordering rituals. More than half of the subjects had severe OCD where according to CY-BOCS revealed that, more than half of the patients had severe OCD (53.3\%) followed by $36.7 \%$ who had extreme OCD, $6.7 \%$ who had moderate OCD, and only $3.3 \%$ who had mild OCD. The proportion of extreme OCD was found to be high among the adolescents (48.7\%) whereas severe OCD was higher among the children $(71.4 \%){ }^{2}$

To date, few studies have done regarding demography and symptom severity of this disorder within a large sample. For this reason, the present study was designed with the main goal of analyzing the demography and symptom severity of this disorder in Bangladesh. This study will give baseline information about demography, co-morbidity and symptom severity of OCD patients and findings of the study will help 
our health professionals. It will also increase the space and will help creating an information baseline to carry out further study in this field in future.

\section{Materials and methods}

This was a cross-sectional study conducted in OCD clinic of outpatient department (OPD) of Bangabandhu Sheikh Mujib Medical University (BSMMU), Dhaka from May, 2015 to April, 2017. BSMMU is one of the biggest tertiary level hospitals in Bangladesh. The data set was composed of 400 consecutive patients with OCD diagnosed according to the Diagnostic and Statistical Manual of Mental Disorders, 4th Edition, Text Revision, (DSM-IV-TR) criteria, who visited the OCD clinic in outpatient department of psychiatry. ${ }^{9}$ Patients who were excluded had with active psychotic disorder, active manic episode, organic brain syndrome, mental retardation, acute substance withdrawal. All the patients were explained about the procedure, its purpose and were assured of confidentiality of the information within informed consent form. Patients were evaluated with a semi-structured interview covering sociodemographic questions, Axis I diagnoses (DSM-IV) and YBOCS severity scale for adult patients through face to face interview. A predetermined questionnaire was filled for each patient. OCD was evaluated on the basis of DSM-IV-TR by a psychiatrist. Trained postgraduate residents in psychiatry directly interviewed the patients and performed all the assessments and a senior consultant expert in assessing OCD subjects confirmed the DSM-IV-TR diagnosis of OCD and associated features by reviewing all the available information. Severity of OCD was assessed by using Bangla version of Yale-Brown Obsessive-Compulsive Scale (Y-BOCS) for adult patients. Data was analyzed using Statistical Package for Social Sciences (SPSS) version 16 for Windows 10.

\section{Results}

The results showed that the mean age of the respondents was $26.6(\mathrm{SD} \pm 9.9)$ years. Most of the respondents were from 21-30-years of age (45.5\%). Out of 400 patients of OCD, 235 $(58.8 \%)$ were male and 165 (41.3\%) were female. Regarding marital status, it was found that most of the patients were unmarried (59.25\%). Majority of the patients completed graduation and post-graduation (32\%), 117(29.25\%) studied up to secondary level and $6(1.5 \%)$ patients were illiterate. Most of the patients came from urban area $(70.5 \%)$. Half of the respondents were students (50\%) followed by $87(21.75 \%$ ) housewives. Among the patients, $58 \%$ had family history of psychiatric disorders (Table 1). According to Y-BOCS symptoms severity scale majority $(70 \%)$ of the patients had moderate to severe sufferings (Figure 1). Among the all respondents $65(16.25 \%)$ had psychiatric co-morbidity (Figure
2). Male had co-morbid anxiety disorders (panic disorder, agoraphobia, social phobia, generalized anxiety disorder) more but female patients were found more depressive disorders (Table 2). On other hand among the all respondents $67(16.75 \%)$ had physical co-morbidity (Figure 3). Female had more hypothyroidism, diabetes, skin disorders and hypertension than male (Table 3).

Table1: Distribution of demographic variables among the respondents $(n=400)$

\begin{tabular}{|c|c|c|}
\hline Demographic variables & Frequency & Percentage \\
\hline \multicolumn{3}{|l|}{ Age (in years) } \\
\hline$<10$ & 6 & 1.5 \\
\hline $10-20$ & 106 & 26.5 \\
\hline $21-30$ & 182 & 45.5 \\
\hline $31-40$ & 65 & 16.3 \\
\hline $41-50$ & 30 & 7.5 \\
\hline $51-60$ & 8 & 2.0 \\
\hline$>60$ & 3 & 0.8 \\
\hline \multicolumn{3}{|l|}{ Gender } \\
\hline Male & 235 & 58.75 \\
\hline Female & 165 & 41.25 \\
\hline \multicolumn{3}{|l|}{ Marital status } \\
\hline Unmarried & 237 & 59.25 \\
\hline Married & 157 & 39.25 \\
\hline Divorced & 4 & 1.0 \\
\hline Separated & 2 & 0.5 \\
\hline \multicolumn{3}{|c|}{ Educational qualification } \\
\hline Illiterate & 6 & 1.5 \\
\hline Primary level & 37 & 9.25 \\
\hline Secondary level & 117 & 29.25 \\
\hline Higher secondary level & 112 & 28.0 \\
\hline Graduate and above & 128 & 32.0 \\
\hline \multicolumn{3}{|l|}{ Living place } \\
\hline Urban & 282 & 70.5 \\
\hline Rural & 118 & 29.5 \\
\hline \multicolumn{3}{|c|}{ Family history of psychiatric disorders } \\
\hline Yes & 232 & 58.0 \\
\hline No & 168 & 42.0 \\
\hline \multicolumn{3}{|l|}{ Occupation } \\
\hline Unemployed & 31 & 7.75 \\
\hline Student & 200 & 50.0 \\
\hline Housewife & 87 & 21.75 \\
\hline Businessman & 12 & 3.0 \\
\hline Service & 61 & 15.25 \\
\hline Others & 9 & 2.25 \\
\hline Total & 400 & 100 \\
\hline
\end{tabular}




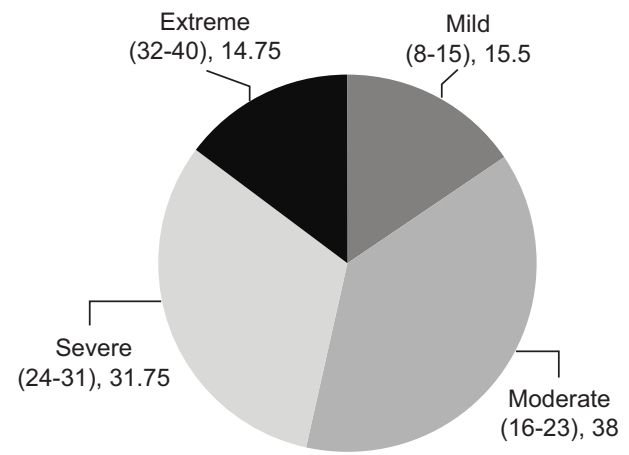

Figure 1: Distribution of severity of OCD according to Y-BOCS among the respondents $(n=400)$

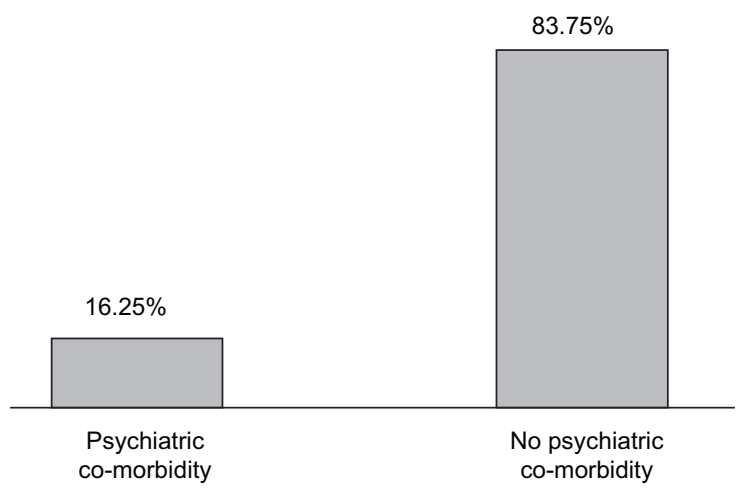

Figure 2: Proportion of psychiatric co-morbidity among the respondents $(n=400)$

Table 2: Distribution of psychiatric co-morbidity according to sex $(n=65)$

\begin{tabular}{lcc}
\hline Psychiatric co-morbidity & \multicolumn{2}{c}{ Participants } \\
\cline { 2 - 3 } & Male $(\mathrm{n}=38)$ & Female $(\mathrm{n}=27)$ \\
\hline Panic disorder & $7.90 \%$ & $3.70 \%$ \\
Social phobia & $18.40 \%$ & $7.40 \%$ \\
Agoraphobia & $7.90 \%$ & $0.00 \%$ \\
Generalized anxiety disorder & $23.70 \%$ & $0.00 \%$ \\
Depressive disorder & $15.80 \%$ & $70.40 \%$ \\
Personality disorder & $2.60 \%$ & $3.70 \%$ \\
Psychotic disorder & $18.40 \%$ & $11.10 \%$ \\
Others & $2.60 \%$ & $0.00 \%$ \\
\hline
\end{tabular}

(More than one co-morbidity were considered in one respondent)

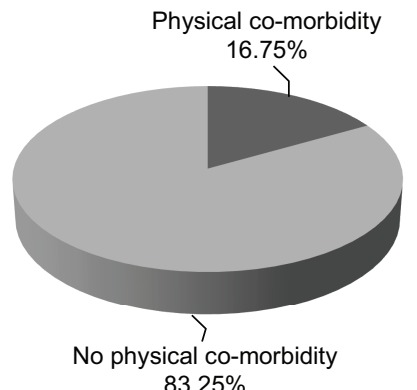

Figure 3: Proportion of physical co-morbidity among the respondents $(n=400)$
Table 3: Distribution of physical co-morbidity according to $\operatorname{sex}(n=67)$

\begin{tabular}{lcc}
\hline Physical co-morbidity & \multicolumn{2}{c}{ Participants } \\
\cline { 2 - 3 } & Male $(\mathrm{n}=32)$ & Female $(\mathrm{n}=35)$ \\
\hline Hypothyroidism & $9.40 \%$ & $20.00 \%$ \\
Diabetes mellitus & $9.40 \%$ & $20.00 \%$ \\
Hypertension & $15.60 \%$ & $17.10 \%$ \\
Skin diseases & $6.30 \%$ & $17.10 \%$ \\
Bronchial asthma & $15.60 \%$ & $5.70 \%$ \\
Others & $34.40 \%$ & $20.00 \%$ \\
\hline
\end{tabular}

(More than one co-morbidity were considered in one respondent)

\section{Discussion}

In the present study it was showed that, the mean age of the respondents was $26.6(S D \pm 9.9)$ years. Most of the respondents were from $21-30$ years of age $(45.5 \%)$. So, the current study reflected that most of the patients were from young age group. This finding is somewhat similar to other studies. In one study, sample mean age of the patients at the time of study was 29.95 years $(S D= \pm 7.91) .{ }^{10}$ Another study done in Bangladesh found that, the mean age of the patients was 29.07 ( $S D \pm 6.11$ ) years and most of the patients $(60.9 \%)$ were in the age range of 20 to 29 years. ${ }^{11,12}$ A Study in Nepal in 2010 found that, about half of the patients were married and majority of them were students and $40 \%$ were come from urban area. They also showed that only $2 \%$ were illiterate and majority of them were better educated. ${ }^{13}$ But, in our study, we found that nearly $60 \%$ were unmarried, $70 \%$ were from urban area and regarding occupation result showed similarity that students were more in numbers. Our study also found that majority were graduate and only $1.5 \%$ were illiterate. This study showed that OCD was found more in literate urban people which indicated good awareness among those patients. This study found that $58 \%$ patients had family history of mental illness. In one study done in Bangladesh 2016, it was found that $45 \%$ of patients had 1 st-degree relatives of psychiatric disorders obtained by history. ${ }^{11}$ Cherianet al., 2014 found that family history of any psychiatric illness and family history of OCD was comparable between both the genders. ${ }^{14}$ This result gives gave further evidence that suggested a biological basis for OCD and genetic studies that found higher concordance rates of OCD in first-degree family members than in general population.

Regarding co-morbid medical illness female had more hypothyroidism, diabetes, skin disorders and hypertensive disorders than male, but bronchial asthma was found more in male patients. On the other hand, male patients were found co-morbid anxiety disorders (panic disorder, agoraphobia, social phobia and generalized anxiety disorder) but female 
patients were found more depressive disorders and personality disorders. In 1999, F Bogetto et al. found that, history of anxiety disorders with onset preceding OCD and hypomanic episodes occurring after OCD onset was significantly more common among males, while females showed more frequently a history of eating disorders. ${ }^{15}$ According to some authors, more women presented cooccurring major depressive disorder. In an Italian study, men presented more social phobia, tic disorders, and hypomanic episodes. ${ }^{16}$ These findings are somewhat consistent with our findings.

In our study $70 \%$ of adult patients had found moderate to severe YBOCS score which corresponded to the Nepalese study where they found, nearly two thirds presented when they had YBOCS score of severe ranges. ${ }^{13} \mathrm{We}$ noted that some of the YBOCS severity scores in our study were their current scores rather than worst-ever scores, and as such, may be a reflection of treatment effects. However, this, and the inclusion of patients with lower levels of severity helps to generalize the findings.

A limitation of this study was that the possibility of recall bias since age at OCD onset was assessed retrospectively. Another limitation of this study was that the current findings might not apply to OCD patients who were not in treatment (community samples) and it was also unclear how generalizability were our findings to other countries and cultures.

\section{Conclusion}

OCD is a common but still undiagnosed psychiatric disorder among people, and that only a small portion of patients receive adequate treatment. There is an immense scarcity of information about this common distressing and disabling disorder in Bangladeshi context. An increased availability of information campaigns would probably allow the early identification and treatment of the disorder, contributing toward symptom relief and a better prognosis.

\section{References}

1. Algin S, Sajib MWH, Arafat SMY. Phenomenology of Obsessive Compulsive Disorder in Bangladesh: a cross-sectional observation. Asian J Psychiatr2018;34:18-20.

2. Chowdhury MHR, Mullick MSI, Arafat SMY. Clinical profile and comorbidity of obsessive-compulsive disorder among children and adolescents: a cross-sectional observation in Bangladesh. Psychiatry J 2016;90:29630.

3. Mullick MSI, Chowdhury MHR, Arafat SMY. Phenomenology of obsessive compulsive disorder in children and adolescents: a cross-sectional observation in Bangladesh. Jentashapir J Health Res 2017;8(4): e63414.

4. Algin S, Arafat SMY, Kushal SA, Ahmed SN, Sajib MWH. Variation in obsessive-compulsive symptoms between children and adults. Bangabandhu Sheikh Mujib Med Univ J 2018;11(2): 130-3.

5. Karno M, Golding J. Obsessive-Compulsive Disorder. In: Psychiatric Disorders in America. The epidemiological catchment area study. New York, NY: The Free Press;1991. p. 204-19.

6. Torres AR, Lima MCP. Epidemiology of obsessive-compulsive disorder: a review. Rev Bras Psiquiatr 2005;27(3):237-42.

7. Riddle MA, Scahill L, King R, Hardin MT, Towbin KE, Ort SI, et al. Obsessive compulsive disorder in children and adolescents: phenomenology and family history. J Am Acad Child Adolesc Psychiatry 1990;29(5):766-72.

8. Leckman JF, Grice DE, Boardman J, Zhang H, Vitale A, Bondi C, et al. Symptoms of obsessive-compulsive disorder. Am J Psychiatry 1997;154(7):911-7.

9. American Psychiatric Association. Diagnostic and Statistical Manual of Mental Disorders, $4^{\text {th }}$ ed (text revision). Washington, DC:American Psychiatric Association; 2000.

10. Chintan S, Jaymin S, Parikh MN,Vankar GK. Gender Differences in Presentation and Phenomenology in Obsessive Compulsive Disorder. Int J Health Sci 2015;2(2):145-52.

11. Ahmed F, Begum M,Wahab MA,Ahmed SK. Quality of life of patients with obsessive compulsive disorder. Bang J Psychiatry 2015;29(1):18-2.

12. Rahman MH, Kamal AHMKM. Obsessive-compulsive disorder a study on clinical phenomenology. JAFMC Bangladesh 2010;6:13-6.

13. Shakya DR. Clinico-demographic profiles in Obsessive Compulsive Disorders. J Nepal Med Assoc 2010;49(178): 133-8.

14. Cherian AV, Narayanaswamy JC, Viswanath B, Guru N, George CM, Bada Math S, et al. Gender differences in obsessivecompulsive disorder: findings from a large Indian sample. Asian JPsychiatr2014;9:17-21.

15. Bogetto F, Venturello S, Albert U, Maina G, Ravizza L. Gender related clinical differences in obsessive-compulsive disorder. Eur Psychiatry 1999;14(8):434-41.

16. Mathis MA, AlvarengaPd, Funaro G, Torresan RC, Moraes I, Torres AR, et al. Gender differences in obsessive-compulsive disorder: a literature review. Rev Bras Psiquiatr2011;33(4): $390-9$. 